and Public Discourse in America. Weiler, Michael and W. Barnett Pearce, eds. Tuscaloosa, Alabama: University of Alabama Press.

Public Discourse in
Peichan Attack on Welfare." Reagan and Pearce, eds. Tuscaloosa, Alabama. Universityael and W. Barnett Weinstein, Deena. 1991. Heary Metal: University of Alabama Press. MacMillan.

hite, John Kenneth. 1988. The New Politics of Old Values. Hanover illiams, J.A. 1966 "Regional Diff England Press.

Forces, 45: 273-277.

Willner, Ann Ruth. 1984. The Spellbinders: Charismatic Political Leadership. New Haven: Yale University Press.

Willner, Dorothy. 1979. "Ritual, Myth, and the Murdered President." Unpublished manuscript obtained from Ann Ruth Willner, Department of Political Science, University of Kansas.

Willner, Ann Ruth and Dorothy Willner. 1965. "The Rise and Role of the Charismatic Leader." Annals of the American Academy of Political and Social Science 358: 77-88.

\section{ERICH FROMM'S CONCEPT OF SOCIAL CHARACTER}

\author{
RAINER FUNK \\ Erich Fromm Archive, Tuebingen
}

Social Thought \& Research, 1998, Vol. 21, No. 1-2

The term "social character" is at the center of Erich Fromm's psychoanalytical thought. The significance of this term in Fromm's approach to psychoanalysis, how he understands it. how it is molded and what its function is will be the first topic of this paper. Since I have already dealt with the concept of social character elsewhere, I would like to confine myself to a summary and say some words on the background against which Fromm developed his psychoanalytical approach.

The term "social character" emerges only at the end of the 1930's. A first systematic description can be found in the appendix of the book Escape from Freedom in the year 1941. The idea behind the concept of "social character", however, had taken shape in Fromm's mind much earlier.

The Fromm literature either connects his own psychoanalytical approach to the Freudo-Marxism of the Frankfurt School or to Harry Stack Sullivan's theory of interpersonal relationship. It is certainly true that Fromm formulated his own (namely social-psychologically-oriented) psychoanalytical approach within the context of the Frankfurt Institute for Social Research. The argument with the members of the Institute in the late thirties, especially Horkheimer, Marcuse, and to a lesser extent Adorno, was sparked off by Freudian instinct theory. Their argument can only be understood if the specifically Frommian approach connecting sociological and psychological thought is taken into account. It was not developed only in the context of the Frankfurt School, but ten years earlier in Fromm's dissertation in 1922 (cf. Fromm 1989b).

1 Copyright 1998 by Dr. Rainer Funk, Ursrainer Ring 24, D-72076 Tuebingen. Germany Tel. 07071-600004; Fax 07071-600049 email: fromm@germanymail.com 
In his dissertation, Fromm examined why Jews living in the Diaspora think, feel and act in a certain way despite the lack of state or church institutions. Fromm's answer to this social-psychological question was: it is a certain way of life of these Diaspora Jews that enables them to passionately realize the spirit of the Torah from within. It was just when Fromm was writing his dissertation with Alfred Weber at Heidelberg University that he first came into contact with Sigmund Freud's psychoanalysis. His own psychoanalytical experience as a patient of Frieda Reichmann in Heidelberg, Wilhelm Wittemberg in Munich, Karl Landauer in Frankfurt and Hanns Sachs in Berlin, as well as his sociological education, enabled him to express his social-psychological thought in the language of Freudian instinct-oriented drive theory and to develop a theory of Freudo-Marxism. Society, Fromm realized, cannot be understood only in terms of its economic, political and cultural structure but primarily in terms of its libidinous structure. Whoever discerns and examines this libidinal structure understands how the socio-economic basis affects the ideas and ideals of a society and that the "basis" and "superstructure" are conveyed by a libidinal structure.

The fact that Fromm, coming from sociology, formulated his psychoanalytical approach as a social-psychological one, is met with resistance by both psychoanalysts and sociologists. Psychoanalysts find the idea of a social unconsciousness hard to accept. On the other hand, sociologists find no use for the unconsciousness of society and direct their interest towards the "external support" and the binding power of institutions and not so much towards the internal structure. Fromm, however, speaks of such a psychic structure of society and of the unconsciousness of society and thereby makes an extremely fruitful new approach to psychoanalysis possible.

If one takes seriously the basic sociological premise that there are forces and patterns that are rooted in society itself-- a premise that is difficult for most psychoanalysts to accept-- then the question can be raised as to whether or not there is something like an unconsciousness of society, and, if so, according to what patterns it develops and whether or not it can be investigated like the unconscious of an individual. If one first accepts the possibility that society has an unconsciousness, which can be called the social unconscious, then the next step is to free oneself from a misguided understanding of society. Fromm emphasizes in his short but important work,
"Psychoanalyse und Soziologie" (1929), that "the subject of sociology, society, in reality consists of individuals... Human beings do not have one 'individual psyche,' which functions when a person performs as an individual and so becomes the object of psychoanalysis, contrasted to a completely separate 'mass psyche' with all sorts of mass instincts, as well as vague feelings of community and solidarity, which spring into action whenever a person performs as part of a mass" (1929; GA I, p. 3). Rather, the individual must be understood as socialized a priori. and thus the psyche is to be understood as being "developed and determined through the relationship of the individual to society" (1929, p. 5).

As the basis for his approach, Fromm refers to statements of Freud's in Group Psychology and the Analysis of the Ego (1921) in order to direct his hypothesis of the socialized individual back at Freud himself, who wrote (Freud 1921, p. 73): "In the individual's mental life someone else is invariably involved, as a model, as an object, as a helper, as an opponent; and so from the very first, individual psychology, in this extended but entirely justifiable sense of the words, is at the same time social psychology as well."

The difference between personal psychology and social psychology can for this reason only be quantitative. Social psychology, just as individual psychology, tries to comprehend psychic structure from the individual's life experiences. So it proceeds according to the same methods: "Social psychology wishes to investigate how certain psychic attitudes common to members of a group are related to their common life experiences" (E. Fromm 1930; GA VI, p. 17).

The idea of "common life experience" is distinguished from the "individual life experience." In the latter it is important to know the sibling order or if someone is the only child; sicknesses and "chance" occurrences of an individual sort are significant because of their strong influence on libidinal structure. On the other hand, the "common life experience" of a group mainly refers to the economic, social and political conditions which determine the way of life for the group. Still completely rooted in the metapsychological concept of Freud's instinct theory, Fromm explained, in probably his best-known essay by the title of "The Method and Function of an Analytic Social Psychology" (1932; GA I, p. 46), that "...the phenomena of social psychology 
are to be understood as processes involving the active and passive adaptation of the instinctual apparatus to and socio-economic situation. In certain fundamental respects, the instinctual apparatus itself is a biological given; but it is highly modifiable. The role of primary formative factors it is highly economic conditions. through which the influence on the individual's situation exerts its formative influence on the individual's psyche. The task of social psychology is to explain the shared, socially relevant, psychic attitudes and ideologies--and their unconscious roots in particular--in terms of the influence of economic conditions in libido strivings."

Fromm had just formulated his psychoanalytical-sociological theory and method between 1929 and 1932 and exemplified it by means of the authoritarian character when the discontent with Freudian instinct theory arose in him. It was above all concerned with the question of the significance of the Oedipus complex and the patriarchal determinism of Freudian libido theory. What occasioned such criticism was mainly Fromm's questioning of the issue of mothers' rights, as interpreted by Morgan, Briffault, and above all Bachofen. It is precisely the social determinism of the Oedipus complex in Freud's interpretation, namely as a typical product of a patriarchal society, that makes the necessity of a different instinct theory evident--one which takes the individual as a social being seriously and regards libidinal structure as independent from the socio-economic situation of the individual.

Fromm's criticism and new formulation of psychoanalytic theory did not come about without other influences. In the group around Georg Groddeck, to which besides Frieda Fromm-Reichmann and Erich Fromm also Karen Horney and Sándor Ferenczi belonged, there was hardly any doubt about the insupportability of the Freudian formulation of the Oedipus complex as early as the late twenties. The thinking of Harry Stack Sullivan, with whom Fromm was friends from 1935 on, proved especially helpful to Fromm's formulation of psychoanalytic theory. Fromm's attempt to regard humans not only as primarily influenced by the unconscious, but also correspondingly as being a reflection of society found expression in Sullivan's "theory of interpersonal relationships." Here psychological development takes on the same significance as the change from forms of primary ties to forms of subjective independent relatedness.
At the end of Escape from Freedom (1941) Fromm summarizes his new formulation with these words: "We believe that man is primarily a social being, and not, as Freud assumes, primarily self-sufficient and only secondarily in need of others in order to satisfy his instinctual needs. In this sense, we believe that individual psychology is fundamentally social psychology or, in Sullivan's terms, the psychology of interpersonal relationships; the key problem of psychology is that of the particular kind of relatedness of the individual toward the world, not that of satisfaction or frustration of single instinctual desires" (1941, p. 290; GA I, p. 387).

It may appear that Fromm rejects all instinct-theoretical thinking. But that is not his point. To be sure, the closer psychoanalytic theory came to being identical to libido theory, the more Fromm tended to formulate his criticism of the libido theory as criticism of Freudian instinct theory in general. Fromm's primary interest of study was also "quasi-instinctive" needs, namely, those which motivate the thoughts, feelings and behavior of humans as social beings. The application of Freud's instinct theory to social groups permitted Fromm to recognize the limited validity of the libido theory and, in 1935, brought him to the recognition that basically two kinds of drives must be distinguished. $\mathrm{He}$ was aware that this distinction introduced a principal disagreement with Freud's instinct theory.

In an unpublished letter of December 18th, 1936 to Karl August Wittfogel, the central idea of Fromm's re-vision of the instinct theory can be discerned clearly. He writes: "The central point of this fundamental disagreement is that 1 try to show that drives which motivate social behavior are not, as Freud assumes, sublimations of sexual instincts. Rather, they are the products of social processes, or, more precisely, reactions to certain constellations under which the individual has to satisfy his/her instincts. These drives, which I divide into those having to do with human relations (love, hate, sadomasochism) and those having to do with methods of acquisition (instincts of receiving, taking away, saving, gathering, producing), are fundamentally different from natural factors, namely the instincts of hunger, thirst, sexuality. Whereas these are common to all human beings and animals, the former are specifically human products and not biological; they are to be understood in the context of the social way of life..." 
Fromm attempts to apply Freud's insight that libidinal structure is molded by life experience to the acknowledgment of the social unconscious. In other words, he comprehends the human being as primarily a reflection of society. In doing this he runs up against the inadequacy of the libido theory explanation. His adherence to the perception that libidinal structure results from adaptation to life experience led him to a new conceptualization of the drive theory, according to which psychological phenomena are disconnected from their physical source, the sex drive, and acquire independence as "psychological drives" as opposed to "physiological drives," among which Fromm includes the drives of self-preservation as well as sexuality.

This re-vision of psychoanalysis also manifests itself in new terminology. Since Fromm used the concept of character for his social-psychological insights, he called drive theory characterology; drive structure became character structure, instinctual impulses became character traits or simply passionate strivings; drive itself is conceptualized as psychological need, libidinal instinct is now called psychological or existential need (in contrast to instinctive or physiological needs); the libidinous structure of a society became the social character, and instead of libido, Fromm, similarly to Jung, now spoke of psychic energy. Due to his contacts with Harry Stack Sullivan, Fromm himself repeatedly connected his re-vision of psychoanalysis to Sullivan's theory of interpersonal relationship. It is true of both that "the key problem of psychology is that of the particular kind of relatedness of the individual toward the world, not that of satisfaction or frustration of single instinctual desires" (1941, p. 290; GA I, p. 387). In the meantime it has become customary-especially in the American reception of Fromm--to understand Fromm as a representative of "object relation psychoanalysis" and to accordingly include him in the "Interpersonal School of Psychoanalysis". (cf. e.g. D. H. Ortmeyer, 1995). As much as it is true that Fromm "was a central figure in the development of the interpersonal approach to psychoanalysis" (1. c., p. 18), as little justice is done to the specifically Frommian approach to psychoanalysis because Fromm does not only look at the individual as being related to others and to society but as a primarily "social" being.

In 1991 I found the manuscript of an essay dating from 1937 that was never published by Fromm because of criticism by Horkheimer, Löwenthal, and Marcuse. This manuscript clearly demonstrates the specifically Frommian approach to psychoanalysis--also in contrast to the approach of Interpersonal Psychoanalysis. Above all, this difference can be elucidated concerning the view of the individual. In this paper fromm explains:

Society and the individual do not stand 'opposite' each other Society is nothing but living, concrete individuals, and the individual can live only as a social human being. His individual life practice is necessarily determined by the life practice of his society or class and in the last analysis, by the manner of production of his society, that means, by how this society produces, how it is organized to satisfy the needs of its members. The differences in the manner of production and life of various societies or classes lead to the development of different character structures typical of the particular society. Various societies differ from each other not only in differences in their manner of production and their social and political organization but also in that their people exhibit a typical character structure despite all individual differences. We call this the 'socially typical character' (Fromm 1992b, p. 222).

Fromm's main interest in looking at the individual is always what here he calls the "socially typical character" and later the "social character". The point is that if you look at any particular person you are primarily confronted with those psychic strivings and impulses, both conscious and unconscious, which this specific person has in common with other persons living under the same socio-economic circumstances; on the other hand, all that makes this person different from, and unique among, other persons living under the same circumstances (his or her special and often traumatic childhood experiences) is--in this respect--of secondary interest. Of course these character orientations and traits were mediated by parents and other "objects" to whom the person was and is related. But these object relations are to be understood as representatives of socially given and molded orientations and expectations.

Doubtless, this way of looking at people is plausible if you study society by analyzing the social character of persons living under similar conditions. But the attraction of this specific psychoanalytic approach is not diminished by looking at an individual or a patient: here you are, in the first instance. acquainted with the social character orientation of a specific person--and it is the social character of a specific person that Fromm is always primarily interested in. We are used to thinking just the opposite, namely that one can only understand 
an individual by looking at the unique conditions and circumstances specific to him. Not so with Fromm:

Just as in all type forming, in the socially typical character only certain fundamental traits are distinguished and these are such that, according to their dynamic nature and their weight, they are of decisit'e importance for all individuals of this society. The fruitfulness of this category is proved in the fact...that analysis traces back the individual's character with all his individual traits to the elements of the socially typical characte and that an understanding of socially typical character is essential to a full understanding of individual character (Fromm 1992b, p. 223; italics added).

I want to emphasize that for Fromm it is the orientation and the traits shared with others that assume decisive importance according to their dynamic nature and weight. This focus on common traits and orientations is just the opposite of our normal way of looking at people and also opposite to the way psychoanalysis looks at patients. Especially in psychotherapy we prefer the individualistic point of view and thereby overestimate what is most individual. We fixate on the highly specific conditions and events in the patient's childhood, what happened there with the object relations and so on. We are used to looking at the individual as an entity clearly distinguished and separated from society, though perhaps endowed with internalized aspects of society (by the Super-Ego or by inner objects); or we see the individual as only secondarily influenced by society, but principally separated from it.

This is not Fromm's way of looking at a person or a patient. In his dissertation about the function of Jewish law, in encountering a patient, or in his analysis of political events, Fromm is always primarily interested in those fundamental traits and orientations that result from a practice of life common to many people, and which are therefore of decisive importance for this specific individual or patient. This is the meaning of his statement that "the individual can only live as a social being." This is, as far as I understand Fromm, the real meaning of his concept of social character and the essence of his social psychological approach to psychoanalysis.

When Fromm embraced the idea of a socially molded unconscious or an unconscious of society by which each individual is predetermined, he defined the Freudian correlation of individual and society anew. After that, it was no longer valid to say "here I am and there is society"; but rather, "I am primarily a reflection of society, in that my unconscious is socially determined and I therefore reflect and realize the secret expectations and wishes, fears and strivings of society in my own expectations and wishes, fears and strivings of society in reality neither the real separation of society and individual nor the real separation of conscious and unconscious, nor the real separation of society and unconscious exist. Both dimensions are in the social unconscious of every single human being.

In my own interpretation of Fromm, I try to understand him rom his Jewish origin and the mental sources shaping him as they are most clearly visible in his dissertation. With the understanding of the relation of individual and society displayed there Fromm received Freudian psychoanalysis and modified his understanding of psychoanalysis until not only the determination of the psychic structure by the way of life, i.e. the determination, individual as a social being, i. e. primarily as a representation of society, and not only as being primarily related (as is claimed by Interpersonal Psychoanalysis).

Fromm's specific psychoanalytic approach shows its fruitfulness both in the analysis of social phenomena and in the understanding of and the therapeutical contact with the understanding of and the therapeutical contact widual can individual human being. Concerning this, the individual can only be understood in his and her normal and neurotic strivings
and drives, if these are discovered as traits and orientations of the social character. Thus the understanding of the individual presupposes the psychoanalysis of society.

Where the psychic energy comes from if it is not the outcome of innate instinctual drives -as Freud explained psychic energy? It was Freud's ingenious idea to see the whole spectrum of human behavior as motivated by libidinal strivings and to understand innate physiological instincts as the source of human passions. The drives (firstly the sexual instinct with its libidinous energy, (the development in which partial instincts and instinctual impulses develop, which express themselves in completely different passionate strivings (sadism, masochism, envy, love etc.)

Fromm sees the origin and differentiation of psychic energy completely differently. For him, the passionate strivings do not 
result from innate instincts, but are rooted in the specific human condition, which expresses itself in specific human needs--as for instance the need for relatedness. Depending on the respective economic and social requirements, these "psychic drives" can be satisfied completely differently. Just because the psychic needs do not have an instinctual source with Fromm, he cannot ascribe the development and differentiation of passionate strivings to the momentum of a drive (as Freud did in his theory of oral, anal, phallic and genital phases and libidinal stages). Instead, the economic and social requirements determine which passionate strivings are developed or not. Thus, with Fromm the respective contemporary historical situation receives a direct molding function: if, in order to function smoothly, a society needs people who are readily submissive, then the passion of submissiveness is the result of this social necessity acquired by identification with this necessity or requirement.

If for Fromm not "instinctual drives," but, rather, the "psychological drives" which lie beyond the physiological needs and are peculiar to human beings - if these psychological needs are the source for our psychic energy, then the question arises of how they originate. The fact that psychic needs are only observable in humans suggests that they should be grounded in the special placement of the human being (his/her conditio humana), and not in the physically-anchored sex drive, which humans have in common with animals. (That does not mean that sexuality is not a very important physiological need for Fromm. But sexuality receives its particular significance because of the fact that sex drive can play an essential role in the satisfaction of the need for relatedness. It is therefore an expression of an ever different kind of object-relatedness and not the other way around, namely that object-relatedness is an expression of an ever different kind of sex drive.) What is the passionate striving of man the result of, if not of instincts rooted in the body? Empathy for the original psychological state of the human being makes the answer evident.

In contrast to instinct-guided animals, man is a contradictory being, characterized "namely by the dichotomy of existing in nature and being subject to all her laws and, at the same time, transcending nature" through his reason, by means of his capacity for imagination and because of his self-consciousness" (1977; GA VIII, p. 244). This peculiarity of the human being creates existential dichotomies with which he must live and to which he must try to answer, without ever being able to resolve the contradictions. Man is thrown into this world without any say and his life is usually ended without his say; he does not know where he came from or where he is going; in his life he always lags behind what he can envision as better and more perfect.

These existential dichotomies are the source of psychic energy. They create psychic needs which are specific to man and for which each person must take responsibility. So, for Fromm, there are not only physical or physiological needs on the one hand are not only physical on the other. There are also independent psychic needs which are governed by their own rules and are therefore not reducible to physiological needs or drives. These psychic needs always have to be satisfied in some way. Their psychic needs alaces the lost instinct-relatedness to the world. To quote Fromm (1977; GA VIII, pp. 245ff.): "The specifically human interest in replacing the lost instinct relatedness to the world with new affective-intellectual forms of relatedness is just as vital as the interest in self-preservation and the sexual interest that humans share with all living beings; it follows from this that the various solutions for the existential contradictions are just as energy-loaden, i.e., passionate, as the manifestations of the ego drives and the libido."

Fromm specified different psychic needs, most importantly, the psychic need for relatedness. The question as to in which way a psychic need for relatednes, in a productive or a non-productive way, essentially depends on what life experience he has had to way, essentially depenth which socio-economic structure he must identify with. Even if a person adopts patterns of relatedness that hinder the development of his psychological possibilities, we see attempts at solutions in which the person reacts to existential dichotomies and produces new patterns of relatedness to the human and natural environment. Even the psychotic, who hallucinates his world, nonetheless satisfies the need for relatedness that is found only in human beings.

The question of productive or non-productive orientation in the satisfaction of psychic needs determines growth and development of psychic possibilities as well as psychic health or sickness. The alternatives of a productive or non-productive solution--or, as Fromm later expressed it, the alternatives of a biophilic or necrophilic, being-oriented or having-oriented solution - determine the progression or regression of the 
psychic system. Psychic health or sickness depends on the orientation one identifies with. A person who has adapted well to the non-productive economic and social structure, who functions well and is capable of working and carrying a load, is in reality the one who is suffering from the pathology of normalcy, the one who is psychologically crippled.

Psychic needs must be satisfied. The way they are satisfied is, however, socially conditioned and is internalized via the family as the agent of society. Fromm expressed the alternative orientations in the satisfaction of needs in terms of respective types and named them according to their objectives. The psychic need for relatedness for instance can either be satisfied productively by a loving orientation or non-productively by a narcissistic orientation. All forms of non-productive relatedness are characterized by the fact that the person stays fixated on the primary ties (fixations) or regresses to them and therefore is alienated from his own forces, whereas the loving satisfaction of the need for relatedness is characterized by the fact that the loving person increasingly becomes the active part in the relationship and creates relatedness to his human and natural environment from his own psychic energies.

Last, but not least, we have to clarify the role that the social character has in social and cultural processes. If we assume that character has the subjective function for each person of leading that person "to act according to what is necessary for him from a practical standpoint and also to give him satisfaction from his activity psychologically" (1941, p. 283; GA I. p. 382f.), then we can maintain that, by function, "the social character internalizes external necessities and thus harnesses human energy for the task of a given economic and social system" (loc. cit., p. 383).

The individual likes to behave the way it has to according to economic and social requirements and expectations. If an economic system is directed toward maximization and quantitative growth one has to make new investments by which new products are created in order to safeguard its functioning. Thus this system needs the individual that loves to consume. What it enjoys doing and what its common sense undoubtedly tells it is reasonable to do--for example, to buy the best bargains at the supermarket and at going-out-of-business sales - that is what it really must do.
"As long as the objective conditions of the society and the culture remain stable, the social character has a predominantly stabilizing function. If the external conditions change in such a way that they do not fit any more with tradition and social character, a lag arises which often makes the character function as an element of disintegration instead of stabilization, as dynamite instead of social mortar, as it were." (1949, p. 6; GA I, p. 211)

In researching social character as dependent on economic and social requirements, essential passionate strivings of man, even unconscious ones that thus originate from the social unconscious, can be recognized and put to profitable use as means of social change. Just how necessary such a recognition of the social character as a productive force is Fromm has the social chated in the thirties by the analysis of authoritarianism. demonstrated in the thirties by the andies he discovered and described the marketing In the forties he discover sixties character orientation (E. Fromm, 19. Fromm, 1964a) as well as the necrophilic character (E. Fromm, 1964; 1973).

\section{References}

Freud, S. 1921. Massenpsychologie und Ich-Analyse Pp. 71-161 in G.W. 13; Group Psychology and the Analysis of the Ego. Pp. 65-143 in S.E. Vol. 18.

Fromm, E. 1989. (GA) Gesamtausgabe in 10 Bänden, herausgegeben von Rainer Funk, Stuttgart (Deutsche Verlag-Anstalt) 1980-1981, München (Deutscher Taschenbuch Verlag).

Gesamtausgabe in 10 Bänden, herausgegeben von Rainer Funk, Stuttgart (Deutsche Verlag-Anstalt) 1980-1981, München (Deutscher Taschenbuch Verlag).

1929. "Psychoanalyse und Soziologie." Pp. 268-70 in Zeitschrift für Psychoanalytische Pädagogik, Wien (Internat. Psychoanalytischer Verlag), Vol. 3 (1928/29); GA I, pp. 3-5. Psychoanalytischer Verlag, Vol. $37-9$ in S. E. Bronner and D. M. Kellner, eds., Critical Theory and Society: A Reader, New York and London: Routledge 1989.

1930. "Die Entwicklung des Christusdogmas. Eine psychoanalytische Studie zur sozialpsychologischen Funktion der Religion." Pp. 305-73 in Imago. Zeitschrift für Anwendung der Psychoanalyse auf die Natur- und 
Geisteswissenschaften. Wien (Internationaler Psychoanalytischer Verlag), Vol. 16; GA VI, pp. 11-68; tranlated into English in The Dogma of Christ and Other Essays (1963).

1931. "Politik und Psychoanalyse." Pp. 440-47 in Psychoanalytische Bewegung, Wien (Internationaler Psychoanalytischer Verlag), Vol. 3; GA I, p. 31-36; translated into English: "Politics and Psychoanalysis." Pp. 213-18 in S. E Bronner and D. M. Kellner, eds., Critical Theory and Society: A Reader. New York and London: Routledge 1989.

1932. "über Methode und Aufgabe einer Analytischen Sozialpsychologie: Bemerkungen über Psychoanalyse und historischen Materialismus." Pp. 28-54 in Zeitschrift für Sozialforschung. Leipzig (Hirschfeld Verlag), Vol. I; GA I, pp. 37-57; translated into English: "The Method and Function of an Analytic Social Psychology." Pp. 135-62 in: The Crisis of Psychoanalysis (1970).

1941. Escape from Freedom. New York: Holt, Rinehart and Winston.

1947. Man for Himself: An Inquiry into the Psychology of Ethics. New York: Rinehart and Co.

1949. "Psychoanalytic Characterology and Its Appllication to the Understanding of Culture." Pp. 1-12 in S.S. Sargent and M.W. Smith, eds., Culture and Personality. New York: Viking Press. German: "Über psychoanalytische Charakterkunde und ihre Anwendung zum Verständnis der Kultur", GA I, p. 207-214.

1963. The Dogma of Christ and Other Essays on Religion, Psychology and Culture. New York: Holt, Rinehart, and Winston.

1964. The Heart of Man: Its Genius for Good and Evil. New York: Harper and Row.

1970. The Crisis of Psychoanalysis: Essays on Freud, Marx and Social Psychgology. New York: Henry Holt.

1973. The Anatomy of Human Destructiveness. New York: Holt, Rinehart, and Winston.

1976. To Have Or to Be? (World Perspectives Vol. 50, planned and edited by Ruth Nanda Anshen). New York: Harper and Row.

1977. "Das psychoanalytische Bild vom Menschen und seine gesellschaftliche Standortbedingtheit." Pp. 243-51 in GA VIII.

. 1989b. Das jüdische Gesetz. Ein Beitrag zur Soziologie des Diasporajudentums. Weinheim und Basel: Beltz-Verlag. In Italian: La legge degli Ebrei. Sociologia della Diaspora ebraica. Milano: Rusconi Editore, 1993. 1992a. Gesellschaft und Seele. Beiträge zur Sozialpsychologie und zur psychoanalytischen Praxis. (Schriften aus dem Nachlaß, Vol. 7), Weinheim and Basel: Beltz.

1992b. "Die Determiniertheit der psychischen Struktur durch die Gesellschaft. Zur Methode und Aufgabe einer Analytischen Sozialpsychologie."Pp. 23-97 in E. Fromm, 1992a. (The page references refer to the German edition; the 1992a. (The page referem the English typoscript which was translated by Erich Fromm himself. Confer the English text translated by http://fromm.home.mc.org).).

Ortmeyer D. H. 1995. "History of the Founders of Interpersonal Psychoanalysis." Pp. 11-27 in Handbook of Interpersonal Psychoanalysis. Hillsdale: The Analytic Press. 